\title{
Aranãs do médio Jequitinhonha: aspectos socioeconômicos, demográficos e sanitários de uma população indígena desaldeada
}

\author{
The Aranãs in mid-Jequitinhonha: socioeconomic, demographic \\ and sanitary aspects of a landless indigenous population
}

Laís Santos de Magalhães Cardoso ${ }^{1}$

Ana Carolina Lanza Queiroz ${ }^{1}$

João Luiz Pena ${ }^{1}$

George Luiz Lins Machado-Coelho ${ }^{2}$

Léo Heller ${ }^{3}$
${ }^{1}$ Escola de Engenharia, Universidade Federal de Minas Gerais. Av. Pres. Antônio Carlos 6627, Campus UFMG. 31270-010 Belo Horizonte MG Brasil.

lilavate23@yahoo.com.br

${ }^{2}$ Departamento de

Ciências Médicas, Escola de Farmácia, Universidade

Federal de Ouro Preto. Ouro Preto MG Brasil.

${ }^{3}$ Centro de Pesquisas René

Rachou, Fiocruz. Belo

Horizonte MG Brasil.
Abstract The lack of epidemiological and environmental data on Brazilian indigenous populations is a challenge for the elaboration of public policy. This lack of data is more acute for "landless" indigenous groups. From this perspective, it was considered relevant to describe the Aranã, a landless indigenous group living in Minas Gerais, focusing on the demographic, socioeconomic and sanitary dimensions. A household survey was conducted. The data collected were analyzed and compared with those from other national ethnic groups. The results revealed similarities between these findings and those from the 2010 Census related to the native indigenous population, especially those not living on indigenous lands or reservations. Asymmetric results were identified within the households, mainly sanitary disparities, which suggested a relation with the location. This result indicates the need for priority intervention for the Arana living in rural areas, bringing to light the age-old discussion about rural and urban disparities. In addition, we suggest that the Brazilian Institute of Geography and Statistics (IBGE), responsible for the 2010 census, should refine its assessment methods concerning landless indigenous groups.

Key words Indigenous population, Demography, Housing, Sanitation, Aranãs
Resumo A deficiência de dados para subsidiar a análise das condições epidemiológicas e ambientais em que vivem os povos indígenas no Brasil constitui desafio para a elaboração de políticas públicas específicas. O déficit informacional é ainda maior para os grupos "desaldeados". Diante desse cenário, julgou-se relevante caracterizar uma população indígena desaldeada, privilegiando as dimensões demográfica, socioeconômica e sanitária. Buscou-se identificar diferenças internas ao grupo e analisar os dados levantados para essa população comparando-os aos de outras etnias. Informações foram obtidas a partir da realização de inquérito domiciliar. Os resultados evidenciaram semelhanças com aqueles revelados pelo Censo 2010 para os indígenas brasileiros, sobretudo para os domiciliados fora das terras indígenas. Foram identificadas assimetrias dentro do grupo, principalmente de ordem sanitária, que sugeriram relação com a localização do domicílio. Apontase para a necessidade de intervenções prioritárias voltadas para os Aranã residentes no meio rural, recaindo na antiga discussão sobre as disparidades urbano-rurais, também aplicada às populações não indígenas. Em adição, sugere-se que o IBGE precisa aprimorar a investigação do contingente populacional indígena desaldeado.

Palavras-chave População indígena, Demografia, Condições habitacionais, Saneamento, Aranã 


\section{Introdução}

Os povos indígenas integram um dos segmentos menos favorecidos da população brasileira no que diz respeito ao acesso a bens e serviços considerados básicos e condicionantes da qualidade de vida e do estado de saúde ${ }^{1,2}$. Apesar dos reconhecidos avanços na saúde para esse segmento, as estatísticas de morbimortalidade revelam ainda persistir um quadro de saúde-doença desfavorável em relação ao da população brasileira em ge$\mathrm{ral}^{3-6}$ As doenças carenciais e infectoparasitárias, comumente associadas ao baixo nível socioeconômico e às condições precárias de saneamento e de moradia, figuram entre as principais causas de morbimortalidade infantil para esse segmento populacional ${ }^{7,8}$. E embora os censos demográficos demonstrem uma tendência de melhora nas condições de saneamento dos domicílios indígenas nos últimos anos, dados do censo 2010 revelam persistirem assimetrias entre as grandes regiões do país, entre os espaços rural e urbano, e entre domicílios dentro e fora das Terras Indígenas $(\mathrm{TI})^{9}$.

Atualmente, são catalogadas 305 etnias habitando terras demarcadas pelo governo, ou dispersas territorialmente em áreas urbanas e rurais de inúmeros municípios brasileiros ${ }^{9}$. Além disso, constata-se o surgimento, ou etnogênese, de comunidades ou povos que reivindicam junto ao governo o reconhecimento de pertencimento a uma etnia - os chamados índios ressurgidos ou emergentes $^{10,11}$. Os processos de etnogênese, de organização e de articulação tomam vulto à medida que ganham força os movimentos indígenas e indigenistas e quando o Estado passa a percebê-los como cidadãos plenos, incluindo suas demandas na agenda pública ${ }^{12,13}$.

Além da pluralidade étnica existente e dos processos de etnogênese, que naturalmente tornam difícil o levantamento e a atualização de dados referentes aos indígenas, outro fenômeno vem trazendo dificuldades: sua presença fora das terras demarcadas. $\mathrm{O}$ último censo ${ }^{9}$ identificou que $42,3 \%$ dos indígenas vivem fora de Terras Indígenas (TI). Apontou que, nas áreas urbanas, $8 \%$ dos indígenas estavam residindo nas TI e $92 \%$ fora dessas terras; inversamente, nas áreas rurais $85,9 \%$ estavam nas terras e $14,1 \%$ fora delas ${ }^{9}$. No entanto, ainda são exíguos os estudos a respeito dos desaldeados, entendidos, no trabalho, como os indígenas que residem fora das TI.

Frente à importância de se lançar luz sobre fração indígena desaldeada, foi realizado um estudo sobre os Aranã. Este integrou uma pesquisa mais abrangente, coordenada pela Universidade Federal de Ouro Preto (UFOP), cujos propósitos foram: determinar a prevalência das parasitoses intestinais em populações indígenas do estado de Minas Gerais; e investigar a relação destas com o estado nutricional dos indivíduos e com as condições ambientais e sanitárias.

O presente artigo buscou caracterizar as dimensões socioeconômica e demográfica dos Aranã, com foco sobre as condições sanitárias de suas habitações; identificar diferenças situacionais internas ao grupo, vez que, apesar de se tratar de uma mesma etnia - o que conotaria certa homogeneidade socioeconômica, cultural e comportamental - parcela reside na zona rural e outra na urbana dos municípios pesquisados; e discutir aspectos socioeconômicos, demográficos e sanitários identificados para os Aranã em comparação com aqueles de outras etnias indígenas nacionais.

\section{Os Aranã contemporâneos}

De acordo com relatório do Centro de Documentação Eloy Ferreira da Silva - CEDEFES ${ }^{14}$, a historiografia oficial aponta ter sido o povo Aranã extinto no século XIX. Os Aranã de outrora integravam um subgrupo dos Botocudos, dispersos na região do vale do rio Doce, Minas Gerais $^{14}$. O presente artigo aborda os Aranã contemporâneos, "originários dos vales do Jequitinhonha e do Mucuri, Minas Gerais"15.

O grupo inseriu-se no movimento indígena e iniciou sua busca pela identificação étnica no final da década de 1990, contando com o auxílio de instituições e pesquisadores, que, recorrendo à historiografia, contribuíram para a legitimação do uso do etnônimo Aranã ${ }^{14}$. Conforme Carvalho $^{16}$, a historiografia foi fundamental para a construção da identidade Aranã, uma vez que existiam lacunas e inconsistências no discurso histórico nativo: "O grupo não sabia, por exemplo, a tribo indígena à qual pertencia [...]. Assim, utilizaram diversos registros históricos para remodelar sua narrativa [...] ou cimentar uma coesão social Aranã [...]”. O reconhecimento étnico dos Aranã contemporâneos pelo governo brasileiro data de $2003^{14}$.

\section{Métodos}

\section{Local do estudo}

O estudo foi realizado nos municípios de Araçuaí e Coronel Murta em função da maior 
concentração familiar dos Aranã ${ }^{14}$. Esses municípios integram a mesorregião Jequitinhonha, situada na região nordeste de Minas Gerais. Araçuaí dista $678 \mathrm{~km}$ da capital mineira, possui área territorial de $2.236 \mathrm{~km}^{2}$ e 36.013 habitantes, sendo $65 \%$ residentes na área urbana ${ }^{17}$. Sobre a situação do saneamento, dos 9.949 domicílios permanentes, a rede geral de distribuição de água atende $72 \%$. A rede de esgotamento sanitário atende $30 \%$, sendo a fossa rudimentar a forma predominante de destinação do esgoto doméstico (53\%). Aproximadamente 65\% dos domicílios têm seu lixo coletado pelo serviço de limpeza urbana municipal, e em $31 \%$ o lixo é queimado ${ }^{17}$.

Coronel Murta possui área territorial de 815 $\mathrm{km}^{2}$ e dista $714 \mathrm{~km}$ da capital mineira. Possui população de 9.117 habitantes, dos quais 73\% residem nas áreas urbanas. $\mathrm{O}$ abastecimento de água atende $72 \%$ dos 2.532 domicílios permanentes. A rede de esgoto $49 \%$ dos domicílios, sendo a fossa rudimentar prevalente (41\%). Aproximadamente $66 \%$ dos domicílios têm seu lixo coletado pelo serviço de limpeza urbana municipal, e em $27 \%$ ele é queimado ${ }^{17}$.

\section{Delineamento da pesquisa e coleta dos dados}

A pesquisa constituiu-se de um survey. A coleta de dados foi realizada nos meses de janeiro, fevereiro e junho de 2012. Dados como idade e data de nascimento, nome, sexo e filiação foram previamente obtidos junto ao Distrito Sanitário Especial Indígena de Minas Gerais e Espírito Santo (DSEI MG/ES). Lideranças indígenas e ex -Agentes Indígenas de Saúde (AIS) atualizaram as listas disponibilizadas e acompanharam os pesquisadores durante o trabalho de campo.

De um total de 114 domicílios identificados, dois não foram efetivamente localizados em função de mudança de endereço dos moradores. O universo da pesquisa compreendeu 112 domicílios geograficamente dispersos: 41 em Araçuaí e 71 em Coronel Murta.

Foram realizados inquéritos domiciliar e parasitológico e, ainda, coleta de amostras intradomiciliares de água para análise microbiológica. $\mathrm{O}$ inquérito domiciliar constituiu-se de questionário subdividido em 11 módulos e abordou: aspectos demográficos, caracterização socioeconômica das famílias, estrutura das casas e do saneamento básico, informações relativas à lavagem das mãos e limpeza do ambiente doméstico e de recipientes utilizados para armazenar água destinada ao consumo humano, estado de saúde dos morado- res e hábitos de vida - como tabagismo e etilismo -, uso de medicamentos, segurança alimentar, aleitamento materno, auxílio financeiro, como recebimento de Bolsa Família ou outro subsídio, caracterização de produção agrícola, não agrícola e pecuária. A aplicação dos questionários teve duração média de uma hora.

Para sua validação, um estudo-piloto foi realizado com aplicação do instrumento em cinco domicílios indígenas, das etnias Aranã e Mokuriñ. Objetivou-se averiguar a necessidade de alterações das questões para adaptação às possíveis particularidades dos povos desaldeados, uma vez que as pesquisas realizadas com as demais etnias do estado englobaram apenas grupos aldeados.

Para a elaboração deste artigo foram utilizadas as informações referentes às variáveis socioeconômicas, demográficas e sanitárias da população, obtidas por meio das questões elaboradas e testadas por Pena ${ }^{18}$, em pesquisa desenvolvida em 2003, que, por sua vez, tiveram como referência os questionários utilizados por Heller ${ }^{19}$ e Teixeira ${ }^{20}$.

\section{Tratamento e análise dos dados}

Todos os dados coletados foram tabulados em planilhas do software SPSS, versão 17.0. Para a caracterização socioeconômica e demográfica da população e a caracterização dos domicílios, incluída a condição sanitária, empregou-se a estatística descritiva. Foram realizadas comparações com dados obtidos na literatura científica e institucional, relativos a outras etnias indígenas brasileiras e também à população brasileira não indígena, incluindo dados sobre a população não indígena residente nas localidades do estudo.

\section{Aspectos éticos}

Atendendo à Resolução 196/96 do Conselho Nacional de Saúde, este estudo foi aprovado pelas lideranças indígenas e pelo Comitê de Ética em Pesquisa da Universidade Federal de Ouro Preto, pela Comissão Nacional de Ética em Pesquisa e pela Fundação Nacional do Índio (FUNAI).

\section{Resultados}

Dos 112 domicílios visitados, a maior parte (62,5\%) localizava-se em áreas urbanas. Parcela expressiva estava na condição de imóvel próprio $(64,3 \%)$ e, nos demais casos, verificou-se maior participação de imóveis cedidos pelo empregador (20,5\%). Esta condição foi mais observada 
para os domicílios das áreas rurais, em que os indivíduos trabalhavam para fazendeiros em troca de moradia e uso da terra para plantio de subsistência. A Tabela 1 apresenta a distribuição dos domicílios segundo localização e situação do imóvel.

No total, foram contabilizados 454 moradores. Pelo inquérito domiciliar, contabilizaram-se 346 indígenas, segundo declaração de cada respondente do questionário. Dentre estes, 204 residiam nas áreas urbanas dos municípios pesquisados e 142 nas áreas rurais. Aqueles declarados como não indígenas totalizaram 108 indivíduos, entre familiares e cônjuges (agregados), sendo 62 residentes nas áreas urbanas e 46 nas rurais. Os pesquisadores optaram pela inclusão dos agregados amparados no pressuposto de que as relações de parentesco ou de vizinhança, constitutivas da comunidade indígena, agregam relações de afinidade, de filiação adotiva, de parentesco ritual ou religioso, conforme sugerido por Castro ${ }^{21}$. A investigação sobre cor da pele ou raça - se branco, pardo ou preto - não foi realizada para os não indígenas.

A partir dos dados levantados no inquérito domiciliar, contabilizou-se média de quatro moradores por domicílio, menos de uma pessoa por cômodo e aproximadamente duas pessoas por dormitório. As razões de sexo calculadas revelaram predomínio feminino nas áreas urbanas $(89,7)$ e um excedente masculino nas rurais $(120,7)$. Identificou-se uma população jovem, na qual $45,4 \%$ dos indivíduos tinham até 24 anos de idade e $47,5 \%$ entre 25 e 64 anos. Os valores mínimo e máximo de idade foram, respectivamente, três meses e 88 anos, e a idade mediana 28 anos. Considerando-se apenas os indivíduos com 10 ou mais anos de idade, identificou-se maior percentual de indivíduos na faixa de 4 a 7 anos de estudo (38,9\%). Estratificando por situação de domicílio, aqueles com maior escolaridade encontravam-se em maior proporção nas áreas urbanas (23,3\%). A Tabela 2 apresenta a distribuição da população Aranã segundo características sociodemográficas.

Identificou-se que o rendimento nominal mensal das famílias residentes nos domicílios indígenas visitados variou até seis salários mínimos, sendo que a maior parte recebia até dois salários (76,8\%). Constatou-se que em 62,5\% dos domicílios os moradores contavam com subsídio financeiro do governo, com maior proporção de beneficiários nas áreas rurais (78,6\%). Em mais de $80,0 \%$ desses domicílios, os moradores declararam receber Bolsa Família. A Tabela 3 apresenta a distribuição dos domicílios habitados por indivíduos da etnia Aranã, segundo características socioeconômicas.

Com relação a características estruturais, $94,6 \%$ dos domicílios possuíam revestimento total do piso interno, estando a maior parte localizada nas áreas urbanas (98,6\%). Especificamente quanto à tipologia das paredes, observou-se uma predominância da alvenaria $(61,6 \%)$, seguida do adobe $(26,8 \%)$. A primeira foi fortemente verificada nas áreas urbanas (80,0\%), enquanto a segunda foi mais frequente nas áreas rurais $(52,4 \%)$. Parte expressiva dos domicílios possuía

Tabela 1. Distribuição dos domicílios segundo localização e situação do imóvel, por situação de domicílio, população Aranã, 2012.

\begin{tabular}{|c|c|c|c|c|c|}
\hline & \multicolumn{4}{|c|}{ Situação de domicílio } & \multirow{3}{*}{$\begin{array}{l}\text { Tota } \\
\text { n }\end{array}$} \\
\hline & \multicolumn{2}{|c|}{ Urbana } & \multicolumn{2}{|c|}{ Rural } & \\
\hline & n & $\%$ & $\mathbf{n}$ & $\%$ & \\
\hline \multicolumn{6}{|l|}{ Municípios } \\
\hline Araçuaí & 31 & 44,3 & 10 & 23,8 & 41 \\
\hline Coronel Murta & 39 & 55,7 & 32 & 76,2 & 71 \\
\hline Total & 70 & 100,0 & 42 & 100,0 & 112 \\
\hline \multicolumn{6}{|l|}{ Situação do imóvel } \\
\hline Próprio & 53 & 75,7 & 19 & 45,2 & 72 \\
\hline Alugado & 11 & 15,7 & - & - & 11 \\
\hline Cedido pelo empregador ${ }^{*}$ & - & - & 23,0 & 54,8 & 23 \\
\hline Cedido por outros ${ }^{* *}$ & 6 & 8,6 & - & - & 6 \\
\hline Total & 70 & 100,0 & 42 & 100,0 & 112 \\
\hline
\end{tabular}

Fonte: Dados primários. "Situação em que o imóvel é cedido pelo dono da fazenda como permuta por trabalho. " Situação em que o imóvel é cedido por familiar. 
Tabela 2. Distribuição dos indivíduos segundo sexo, idade e escolaridade, por situação de domicílio - população Aranã, 2012.

\begin{tabular}{|c|c|c|c|c|c|c|}
\hline & \multicolumn{4}{|c|}{ Situação de domicílio } & & \\
\hline & \multicolumn{2}{|c|}{ Urbana } & \multicolumn{2}{|c|}{ Rural } & \multicolumn{2}{|c|}{ Total } \\
\hline & $\mathbf{n}$ & $\%$ & $\mathbf{n}$ & $\%$ & $\mathbf{n}$ & $\%$ \\
\hline \multicolumn{7}{|l|}{ Sexo } \\
\hline Feminino & 136 & 52,7 & 82 & 45,3 & 218 & 49,7 \\
\hline Masculino & 122 & 47,3 & 99 & 54,7 & 221 & 50,3 \\
\hline Total & 258 & 100,0 & 181 & 100,0 & $439^{*}$ & 100,0 \\
\hline Razão de sexo & & 89,7 & & 120,7 & & 101,4 \\
\hline \multicolumn{7}{|l|}{ Idade } \\
\hline 0 a 14 anos & 71 & 27,5 & 49 & 27,5 & 120 & 27,5 \\
\hline 15 a 19 anos & 25 & 9,7 & 22 & 12,4 & 47 & 10,8 \\
\hline 20 a 24 anos & 17 & 6,6 & 14 & 7,9 & 31 & 7,1 \\
\hline 25 a 64 anos & 125 & 48,4 & 82 & 46,1 & 207 & 47,5 \\
\hline 65 ou mais anos & 20 & 7,8 & 11 & 6,2 & 31 & 7,1 \\
\hline Total & 258 & 100,0 & 178 & 100,0 & $436^{* *}$ & 100,0 \\
\hline mínimo & & & & & \multirow{3}{*}{\multicolumn{2}{|c|}{$\begin{array}{l}3 \text { meses } \\
88 \text { anos } \\
28 \text { anos }\end{array}$}} \\
\hline máximo & & & & & & \\
\hline mediana & & & & & & \\
\hline \multicolumn{7}{|c|}{ Escolaridade (anos de estudo) ${ }^{* * *}$} \\
\hline menos de 1 ano & 22 & 10,5 & 22 & 15,2 & 44 & 12,4 \\
\hline 1 a 3 anos & 26 & 12,4 & 24 & 16,6 & 50 & 14,1 \\
\hline 4 a 7 anos & 80 & 38,1 & 58 & 40,0 & 138 & 38,9 \\
\hline 8 a 10 anos & 33 & 15,7 & 21 & 14,5 & 54 & 15,2 \\
\hline 11 ou mais anos & 49 & 23,3 & 20 & 13,8 & 69 & 19,4 \\
\hline Total & 210 & 100,0 & 145 & 100,0 & 355 & 100,0 \\
\hline
\end{tabular}

Fonte: Dados primários. ${ }^{*}$ Sem essa informação para 15 sujeitos. ${ }^{* *}$ Sem essa informação para 18 sujeitos. ${ }^{* *}$ Os anos de estudo se referem apenas aos indivíduos com 10 ou mais anos de idade. Não se obteve essa informação para 19 sujeitos.

Tabela 3. Distribuição dos domicílios segundo renda mensal das famílias e recebimento de subsídio financeiro, por situação de domicílio - população Aranã, 2012.

\begin{tabular}{|c|c|c|c|c|c|c|}
\hline & \multicolumn{4}{|c|}{ Situação de domicílio } & & \\
\hline & \multicolumn{2}{|c|}{ Urbana } & \multicolumn{2}{|c|}{ Rural } & \multicolumn{2}{|c|}{ Total } \\
\hline & $\mathbf{n}$ & $\%$ & n & $\%$ & n & $\%$ \\
\hline \multicolumn{7}{|c|}{ Renda mensal (salários mínimos) } \\
\hline Até $1 / 2$ & 7 & 10,0 & 8 & 19,0 & 15 & 13,4 \\
\hline $1 / 2$ até 2 & 46 & 65,7 & 25 & 59,5 & 71 & 63,4 \\
\hline Mais de 2 & 17 & 24,3 & 9 & 21,4 & 26 & 23,2 \\
\hline Total & 70 & 100,0 & 42 & 100,0 & 112 & 100,0 \\
\hline \multicolumn{7}{|l|}{ Subsídio financeiro } \\
\hline Sim & 37 & 52,9 & 33 & 78,6 & 70 & 62,5 \\
\hline Não & 33 & 47,1 & 9 & 21,4 & 42 & 37,5 \\
\hline Total & 70 & 100,0 & 42 & 100,0 & 112 & 100,0 \\
\hline \multicolumn{7}{|l|}{ Tipo de subsídio } \\
\hline Bolsa família & 34 & 91,9 & 27 & 81,8 & 61 & 87,2 \\
\hline Bolsa escola & 3 & 8,1 & 5 & 15,2 & 8 & 11,4 \\
\hline Bolsa alimentação & - & - & 1 & 3,0 & 1 & 1,4 \\
\hline Total & 37 & 100,0 & 33 & 100,0 & 70 & 100,0 \\
\hline
\end{tabular}

Fonte: Dados primários. 
algum tipo de revestimento das paredes internas $(90,2 \%)$ e externas $(85,7 \%)$, sendo verificada, em geral, a presença de reboco com camada de tinta ou de cal. Os domicílios com paredes internas totalmente revestidas encontravam-se majoritariamente nas áreas urbanas $(91,4 \%)$, assim como paredes externas totalmente revestidas (90,0\%).

Quando questionados sobre a existência de banheiro, respondentes de 14 domicílios afirmaram não possuir tal cômodo. Do total de domicílios nessa condição, a maioria $(\mathrm{n}=12)$ localizava-se nas áreas rurais. Quanto aos 98 domicílios com banheiro, identificou-se que em 70,4\% o cômodo integrava a parte interna da moradia, em $28,6 \%$ localizava-se na parte externa; em apenas $1 \%$ verificou-se existência de banheiro dentro e fora da moradia (dados não mostrados). Ainda com relação aos domicílios que alegaram possuir banheiro, 89,8\% referiram-se a um cômodo delimitado, com vaso sanitário, chuveiro e lavatório.

Apenas um domicílio, localizado na área rural, não possuía luz elétrica. A Tabela 4 sintetiza as características estruturais dos domicílios habitados pela população Aranã.

Quanto à origem da água de abastecimento utilizada no domicílio, verificou-se que a maioria utilizava a proveniente da rede geral do Sistema de Abastecimento de Água da Companhia de Saneamento de Minas Gerais - SAA da COPASA/ Copanor $(n=66 / 58,9 \%$ ), todos localizados em zonas urbanas. Nos demais, verificou-se utilização de água de nascente $(\mathrm{n}=21 / 18,8 \%)$, de rio $(\mathrm{n}=$ $9 / 8,0 \%)$, cacimba $(n=2 / 1,8 \%)$, riacho ou ribeirão $(\mathrm{n}=1 / 0,9 \%)$ e de fontes mistas $(\mathrm{n}=13 / 11,6 \%)$.

Em relação à destinação das excretas dos domicílios que possuíam banheiro $(\mathrm{n}=98)$, apenas

Tabela 4. Características estruturais dos domicílios, segundo situação de domicílio - população Aranã, 2012.

\begin{tabular}{|c|c|c|c|c|c|}
\hline & \multicolumn{4}{|c|}{ Situação de domicílio } & \multirow{3}{*}{$\begin{array}{c}\text { Tota } \\
\mathbf{n}\end{array}$} \\
\hline & \multicolumn{2}{|c|}{ Urbana } & \multicolumn{2}{|c|}{ Rural } & \\
\hline & n & $\%$ & $\mathbf{n}$ & $\%$ & \\
\hline \multicolumn{6}{|l|}{ Tipologia do piso interno } \\
\hline Totalmente revestido & 69 & 98,6 & 37 & 88,1 & 106 \\
\hline Parcialmente revestido & 1 & 1,4 & 3 & 7,1 & 4 \\
\hline Sem revestimento & - & - & 2 & 4,8 & 2 \\
\hline Total & 70 & 100,0 & 42 & 100,0 & 112 \\
\hline \multicolumn{6}{|l|}{ Tipologia das paredes } \\
\hline Tijolos de barro (alvenaria) & 56 & 80,0 & 13 & 31,0 & 69 \\
\hline Adobe & 8 & 11,4 & 22 & 52,4 & 30 \\
\hline Blocos de cimento & 3 & 4,3 & - & - & 3 \\
\hline Enchimento & - & - & 1 & 2,4 & 1 \\
\hline Misto (combinação dos materiais acima) & 3 & 4,3 & 6 & 14,3 & 9 \\
\hline Total & 70 & 100,0 & 42 & 100,0 & 112 \\
\hline \multicolumn{6}{|l|}{ Revestimento das paredes internas } \\
\hline Revestidas & 64 & 91,4 & 37 & 88,1 & 101 \\
\hline Parcialmente revestidas & 1 & 1,4 & - & - & 1 \\
\hline Sem revestimento & 5 & 7,1 & 5 & 11,9 & 10 \\
\hline Total & 70 & 100,0 & 42 & 100,0 & 112 \\
\hline \multicolumn{6}{|l|}{ Revestimento das paredes externas } \\
\hline Revestidas & 63 & 90,0 & 33 & 78,6 & 96 \\
\hline Parcialmente revestidas & 1 & 1,4 & 3 & 7,1 & 4 \\
\hline Sem revestimento & 6 & 8,6 & 6 & 14,3 & 12 \\
\hline Total & 70 & 100,0 & 42 & 100,0 & 112 \\
\hline \multicolumn{6}{|l|}{ Existência de banheiro } \\
\hline Sim & 68 & 97,1 & 30 & 71,4 & 98 \\
\hline Não & 2 & 2,9 & 12 & 28,6 & 14 \\
\hline Total & 70 & 100,0 & 42 & 100,0 & 112 \\
\hline \multicolumn{6}{|l|}{ Luz elétrica } \\
\hline Sim & 70 & 100,0 & 41 & 97,6 & 111 \\
\hline Não & - & - & 1 & 2,4 & 1 \\
\hline Total & 70 & 100,0 & 42 & 100,0 & 112 \\
\hline
\end{tabular}

Fonte: Dados primários. 
$36,1 \%$ estavam ligados à rede geral coletora de esgoto, todos localizados em zonas urbanas, enquanto $51,5 \%$ possuíam fossas. A estratificação por situação de domicílio revelou que $42,6 \%$ daqueles com banheiro, localizados na área urbana, tinham a fossa como destinação das excretas. Em quatro domicílios com banheiro, situados na área rural, os moradores relataram a prática de defecação a céu aberto.

No que se refere aos domicílios que não dispunham de banheiro $(n=14)$, em $64,3 \%$ os moradores relataram defecação a céu aberto, em 28,6\% utilização de banheiros de residências vizinhas, habitadas por parentes, e em apenas um domicílio o morador relatou utilizar fossa seca $(7,1 \%)$. Sobre a destinação do lixo, verificou-se que 56,3\% dos domicílios tinham acesso à coleta municipal (56,3\%), todos localizados nas áreas urbanas. Em parcela expressiva foi reportada prática de queima dos resíduos (40,2\%), majoritariamente realizada nas áreas rurais $(95,2 \%)$. Os dados referentes ao saneamento nos domicílios habitados pelos Aranã estão dispostos na Tabela 5.

\section{Discussão}

\section{Características demográficas}

Informação obtida através do Sistema IBGE de Recuperação Automática - SIDRA - referente ao Censo demográfico de 2010 aponta um total de 210 pessoas que se declararam indígenas pertencentes à etnia Aranã: 108 homens e 102 mulheres. Deste universo, 184 indivíduos residiam na região Sudeste, 14 na região Sul, 7 no

Tabela 5. Características sanitárias dos domicílios, segundo situação de domicílio - população Aranã, 2012.

\begin{tabular}{|c|c|c|c|c|c|}
\hline \multirow{3}{*}{ Situação sanitária dos domicílios } & \multicolumn{4}{|c|}{ Situação de domicílio } & \multirow{3}{*}{$\begin{array}{c}\text { Tota } \\
\mathbf{n}\end{array}$} \\
\hline & \multicolumn{2}{|c|}{ Urbana } & \multicolumn{2}{|c|}{ Rural } & \\
\hline & $\mathbf{n}$ & $\%$ & $\mathbf{n}$ & $\%$ & \\
\hline \multicolumn{6}{|l|}{ Abastecimento de água } \\
\hline Rede municipal & 66 & 94,3 & - & - & 66 \\
\hline Mina/nascente & - & - & 21 & 50,0 & 21 \\
\hline Rio & - & - & 9 & 21,4 & 9 \\
\hline Riacho/ribeirão & - & - & 1 & 2,4 & 1 \\
\hline Cacimba & - & - & 2 & 4,8 & 2 \\
\hline Fontes mistas & 4 & 5,7 & 9 & 21,4 & 13 \\
\hline Total & 70 & 100,0 & 42 & 100,0 & 112 \\
\hline \multicolumn{6}{|l|}{ Esgotamento sanitário } \\
\hline \multicolumn{6}{|l|}{ Possui banheiro } \\
\hline Rede municipal & 35 & 51,5 & - & - & 35 \\
\hline Fossa & 29 & 42,6 & 21 & 72,4 & 50 \\
\hline Encanado para o terreno & 1 & 1,5 & 1 & 3,4 & 2 \\
\hline Fossa seca (buraco para dejeção) & 1 & 1,5 & 1 & 3,4 & 2 \\
\hline Canalizado para córrego & 2 & 2,9 & - & - & 2 \\
\hline Encanado para terreno longe de casa & - & - & 2 & 6,9 & 2 \\
\hline Céu aberto & - & - & 4 & 13,8 & 4 \\
\hline Total com banheiro & 68 & 100,0 & $29^{*}$ & 100,0 & 97 \\
\hline \multicolumn{6}{|l|}{ Não possui banheiro } \\
\hline Céu aberto & - & - & 9 & 75,0 & 9 \\
\hline Fossa seca (buraco para dejeção) & - & - & 1 & 8,3 & 1 \\
\hline Outro local & 2 & 100,0 & 2 & 16,7 & 4 \\
\hline Total sem banheiro & 2 & 100,0 & 12 & 100,0 & 14 \\
\hline \multicolumn{6}{|l|}{ Resíduos sólidos } \\
\hline Coleta pública & 63 & 90,0 & - & - & 63 \\
\hline Queima no quintal & 5 & 7,1 & 40 & 95,2 & 45 \\
\hline Descarte no solo & - & - & 1 & 2,4 & 1 \\
\hline Práticas mistas & 2 & 2,9 & 1 & 2,4 & 3 \\
\hline Total & 70 & 100,0 & 42 & 100,0 & 112 \\
\hline
\end{tabular}

Fonte: Dados primários. * Sem essa informação para um domicílio da área rural. 
Nordeste, 3 no Norte e 2 no Centro-Oeste do país. Diferentemente, o relatório do CEDEFES ${ }^{14}$ descreveu sua presença apenas em municípios de Minas Gerais e no de São Paulo, tanto nas áreas urbanas, quanto nas rurais.

Os resultados do inquérito domiciliar indicaram um número maior de pessoas pertencentes à etnia indígena Aranã $(n=346)$, o que sugere um descompasso entre as fontes de informação, tanto no que se refere ao contingente populacional, quanto à sua distribuição pelo território nacional. Pode-se pensar em uma defasagem temporal do relatório do CEDEFES, haja vista a data de sua publicação (2003). Todavia, os dados coletados em 2012 pelo inquérito domiciliar (um ano e três meses após coleta do Censo 2010) podem indicar a necessidade de se aprimorar a investigação pelo IBGE sobre os indígenas que residem fora das TI.

Marinho et al. ${ }^{22}$, apontaram problemas na forma de captação de dados referentes aos indígenas em levantamentos realizados pelo Instituto e também sugeriram a necessidade de seu aprimoramento. O próprio IBGE $^{9}$ mencionou alguns fatores que dificultaram a caracterização desse segmento populacional brasileiro, sob o ponto de vista demográfico, dentre eles o fato de populações indígenas residirem em áreas rurais de difícil acesso. Outro ponto crítico remete a um possível viés metodológico que pode comprometer a contabilização daqueles residentes fora das $\mathrm{TI}^{9}$. A constatação de que o levantamento censitário com base apenas no quesito cor ou raça poderia "levar a possível subenumeração dos indígenas no País" levou o IBGE a inserir a seguinte pergunta controle: "Você se considera indígena?". Entretanto, o Instituto parece ter considerado apenas as respostas relativas aos residentes de TI, conforme a passagem a seguir:

Conforme mencionado anteriormente, a população indígena residente no Brasil contabilizada pelo quesito cor ou raça atingiu 817,9 mil pessoas e agregando-se aquelas pessoas que não se declararam indígenas no quesito cor ou raça, mas se consideraram indígenas captadas dentro das terras indígenas, o total de população indígena residente no território nacional passou a 896,9 mil pessoas, o que corresponde a um acréscimo de 78,9 mil indigenas (grifo dos autores) ${ }^{9}$.

No que diz respeito à razão de sexo observada na população Aranã, esta indicou um equilíbrio entre ambos. A estratificação dos dados por situação de domicílio indicou, no entanto, o predomínio de indivíduos do sexo feminino nas áreas urbanas, e excedente masculino nas áreas rurais. Esse mesmo padrão pode ser observado para a população indígena nacional, na qual a razão de sexo total, para o ano de 2010, foi equivalente a 100,5; para as áreas urbanas foi igual a 92,1; e para as rurais, igual a $106,1^{9}$. Franceschini et al. ${ }^{23}$ afirmam que no Vale do Jequitinhonha a população é caracterizada, na sua maioria, e especialmente na área rural, por homens, refletindo o perfil das atividades econômicas da região (pecuária e a agricultura de subsistência). Quanto à estrutura por idade, verifica-se semelhança entre os dados apresentados para a população Aranã e aqueles relativos à população indígena brasileira: ambas são populações jovens. Os dados do Censo $2010^{9}$ revelaram que $94,4 \%$ da população indígena no país possuíam menos de 64 anos.

Quanto ao nível educacional dos indivíduos Aranã, mensurado por meio do indicador anos de estudo, a maior proporção de indivíduos concentrou-se na faixa de 4 a 7 anos (38,9\%). Essa situação diverge daquela apresentada para a população brasileira pela Pesquisa Nacional por Amostra de Domicílios (PNAD) ${ }^{24}$, referente ao ano de 2012, cujos dados apontaram maior proporção de indivíduos com 10 ou mais anos de idade concentrada na faixa de 11 anos ou mais de estudo $(36,1 \%)$.

\section{Características socioeconômicas}

Nota Técnica emitida em 2011 pelo Ministério do Desenvolvimento Social e Combate à Fome $(\mathrm{MDS})^{25}$ com base em dados preliminares do Censo Demográfico 2010, apontou um perfil da pobreza no Brasil e revelou que quatro em cada dez indígenas se encontram em situação de extrema pobreza - caracterizada pelo recebimento de até 70 reais per capita, por mês. Cumpre esclarecer que no caso dos Aranã o rendimento mensal domiciliar mostrou-se variável e pode não representar fidedignamente sua situação econômica, pelo fato de muitos indivíduos, principalmente na área rural, receberem o ordenado por dia de trabalho, e esses dias variarem sazonalmente.

Verificou-se que os moradores de grande parcela dos domicílios Aranã recebem algum tipo de auxílio financeiro do governo. Essa constatação vai ao encontro de estudos que abordam a temática, como o realizado com os Kaingang e Guarani, que identificou os respectivos percentuais de famílias beneficiadas pelo Programa Bolsa Família (PBF): $80,5 \%$ e $57,5 \%{ }^{26}$, respectivamente. Estudo realizado com os Pataxó apontou um percentual de $75 \%$ de famílias beneficiadas ${ }^{27}$. Percentual semelhante foi levantado para os Terena (71,4\%), sendo atribuído, contudo, não só a esse 
programa de distribuição direta de renda, mas a outros como o Bolsa-Escola ${ }^{28}$. Para os povos das etnias Atikun e Guarani-Kaiowá os benefícios assistenciais constituem a principal renda, visto que aproximadamente $90 \%$ das famílias recebem recursos do $\mathrm{PBF}^{29,30}$. Esses percentuais sugerem que as famílias indígenas, em geral, "atendem aos critérios de pobreza e extrema pobreza" ${ }^{31}$.

Em uma abordagem comparativa com a região onde vivem os Aranã, pode-se lançar mão do estudo realizado por Ribeiro et al. ${ }^{32}$, que revelou que os programas de transferência constituem fontes de renda generalizadas; seguida da venda da produção agrícola, do trabalho para terceiros e das aposentadorias e pensões. Reporta, por exemplo, que no município de Araçuaí 44,26\% da população é atendida pelo PBF.

Instituído pelo governo federal no ano de 2003, esse Programa beneficiou, conforme dados de 2011, cerca de 13.077.263 famílias no país, dentre as 21.713 .578 registradas no Cadastro Único para Programas Sociais do Governo Federal (CadÚnico), representando um percentual de $60,2 \%{ }^{33}$. Comparativamente, nesse mesmo período, o número total de famílias indígenas cadastradas foi de 112.314, sendo que as efetivamente beneficiárias do PBF chegaram a 84.940, correspondendo a um percentual mais elevado para esse segmento populacional, de $76 \%{ }^{33}$.

Quanto à situação do imóvel, identificou-se que maior parte dos domicílios Aranã encontrava-se na condição de próprio, o que vai ao encontro dos dados apresentados pelo Censo 2010, que revelou que uma maior proporção de domicílios com pelo menos um morador indígena encontrava-se nesta condição $(75,6 \%)^{9}$. Constatou-se também que nas áreas rurais a maior parte dos imóveis se encaixava na categoria "cedido pelo empregador" (54,8\%), o que parece refletir uma peculiaridade do contexto rural do Vale do Jequitinhonha: às famílias que trabalham em fazendas e áreas de plantio é dada a permissão para residir em moradia cedida pelo empregador, fazendo uso do solo para cultivo de subsistência, constituindo, assim, um "regime de agregação" ${ }^{34}$. Configura-se uma relação de trabalho e "relação de morada, que implica a execução de tarefas para o fazendeiro que cede a terra e a produção dos meios de vida, por parte do agregado ${ }^{35 "}$ e de sua família.

\section{Características estruturais e perfil sanitário dos domicílios}

Os resultados permitiram inferir que, no geral, as características estruturais e sanitárias das habitações Aranã não refletem o quadro de insalubridade verificado em etnias residentes em Terras Indígenas, como os Xakriabá ${ }^{36}$ ou os Maxakali $^{37}$. Para os Aranã foram identificados, por exemplo, maiores percentuais de revestimento do piso interno e das paredes, e de existência de banheiro nos domicílios.

Pisos revestidos podem facilitar a limpeza do domicílio, e, assim, interferir de modo preventivo no mecanismo de transmissão de doenças de veiculação feco-oral ${ }^{38}$. O revestimento de paredes, por sua vez, pode ser uma importante estratégia na eliminação de frestas, possíveis alojamentos para insetos, como o Triatoma infestans.

A maior parte dos domicílios Aranã possuía banheiro, entendido como cômodo delimitado com vaso sanitário, chuveiro e lavatório, na parte interna da moradia (70,4\%). Sob a perspectiva da Engenharia Sanitária, essa pode ser considerada condição ideal em termos de conforto, higiene, prevenção de transmissão de patógenos, e saneamento do meio, principalmente em função da disposição adequada dos excretas (não necessariamente sua destinação adequada). Quanto à existência de banheiro, os dados relativos aos Aranã diferiram daqueles oriundos do I inquérito Nacional de Saúde e Nutrição Indígena ${ }^{39}$, o qual indicou que 19\% dos domicílios indígenas em todo o país dispunham desse cômodo dentro de casa. Entretanto, há que se considerar que esse inquérito, embora tenha representatividade nacional e regional, baseou-se em uma amostra de populações indígenas aldeadas.

Segundo o IBGE $(2010)^{9}, 55,0 \%$ dos domicílios indígenas no território nacional faziam uso de soluções alternativas de abastecimento como fonte de água para consumo, principalmente poço artesiano. Os dados levantados sobre os Aranã revelaram que a cobertura pela rede de abastecimento de água era predominante em relação às demais formas (58,9\%); resultado de certa forma esperado, dada sua concentração domiciliar nas áreas urbanas. Entretanto, quando comparado com dados do último censo, esse percentual de acesso à rede está bem aquém dos $80 \%$ apontados para os domicílios indígenas localizados fora das TI no território nacional ${ }^{9}$. Ademais, o percentual de cobertura da rede de esgoto para os Aranã $(36,1 \%)$ contrasta com as proporções reveladas para a população brasileira $(67,1 \%)$ e até mesmo para o segmento indígena nacional $(57,8 \%)^{9}$.

$\mathrm{Na}$ tentativa de compreender essas assimetrias sanitárias, é preciso atentar para o fato de os domicílios Aranã estarem localizados no Vale do Jequitinhonha, conhecido por apresentar baixos 
indicadores sociais e econômicos. Tanto em Araçuaí, quanto em Coronel Murta, a rede coletora de esgotos atendia, em 2010, menos de 50\% dos domicílios, sendo os percentuais de cobertura iguais a $30 \%$ e $44 \%$, respectivamente ${ }^{40}$. Por sua vez, o percentual de domicílios Aranã com acesso à coleta municipal de lixo (56,3\%) corrobora o percentual apresentado pelo último censo para a população indígena brasileira, de 59,8\%. Entretanto, difere da proporção identificada para a totalidade da população brasileira, para a qual $87,4 \%$ dos domicílios contavam com a coleta do lixo domiciliar ${ }^{17}$.

Para os Aranã, o serviço de coleta abrangia unicamente a área urbana, sendo a prática de queima verificada para o meio rural. Essa realidade, constatada na zona rural, se assemelhou àquela relatada em outros estudos para populações ou grupos indígenas aldeados. O I Inquérito Nacional de Saúde e Nutrição Indígena ${ }^{39}$, por exemplo, identificou que $79 \%$ do total de domicílios das quatro macrorregiões do país enterravam, queimavam ou jogavam o lixo no entorno das aldeias. Em trabalho realizado com os Baniwa do Noroeste Amazônico, 100\% dos entrevistados informaram enterrar ou queimar o lixo doméstico ${ }^{41}$. O mesmo ocorrendo com a maior parte dos domicílios Xakriabá ${ }^{36}$, e também para os Iauaretêt $\hat{}^{42}$, em São Gabriel da Cachoeira.

Sabe-se que nas áreas rurais é difícil propiciar condições de acesso a infraestruturas, equipamentos e serviços especializados, tendo em vista a grande dispersão da população ${ }^{43}$. No entanto, é preciso ponderar que o débito histórico do país com as comunidades rurais em relação às ações de saneamento não pode ser justificado apenas por suas peculiaridades locais.

\section{Conclusões}

Apesar do alto contingente de indígenas vivendo fora das TI, o fato de estudos existentes ainda enfocarem prioritariamente as populações aldeadas, constitui claro exemplo do objeto de questionamento de Nunes ${ }^{44}$ : seriam os indígenas urbanos considerados "menos índios que os outros índios"? Apropriando desse questionamento e extrapolando-o para o segmento indígena desaldeado - independentemente da localização no espaço urbano ou rural - torná-lo visível para o Estado constitui tarefa para além das pesquisas acadêmicas ou encampadas por organizações não governamentais. Essa visibilidade configura-se "ferramenta potencialmente poderosa para municiar segmentos sociais marginalizados na busca de políticas e práticas que pressionem em direção a uma maior equidade em saúde" 45 e em outras esferas dos direitos sociais.

Conhecer as características dos domicílios Aranã permitiu identificar as condições em que vivem, possibilitando a realização de comparações com outras populações, indígenas ou não. Importante ressaltar, no entanto, que a escassez de estudos que abordam as condições de saneamento e de moradia de populações indígenas que não residem em TI limitou a comparar os resultados encontrados com os de outras situações similares. Os dados encontrados para os Aranã evidenciaram semelhanças com aqueles revelados pelo Censo 2010 para os indígenas brasileiros, sobretudo com os domiciliados fora das TI. No entanto, os dados coletados nesta pesquisa sobre os Aranã sugerem que o IBGE precisa aprimorar a investigação acerca das populações indígenas brasileiras "desaldeadas".

Ainda que se observe no país uma assimetria entre indígenas e não indígenas no que se refere à situação de saneamento dos domicílios, o estudo revelou que existem discrepâncias internas ao grupo Aranã. As habitações, em suas características estruturais mais gerais, apresentaram diferenças relacionadas à sua localização, como maior cobertura de abastecimento de água e esgotamento sanitário nas áreas urbanas. Tal observação aponta para a necessidade de intervenções prioritárias voltadas para os indivíduos residentes no meio rural, recaindo na antiga discussão sobre as disparidades urbano-rurais, que também se aplica à população não indígena.

\section{Colaboradores}

LSM Cardoso propôs o tema desenvolvido, realizou a pesquisa empírica e redigiu o artigo. ACL Queiroz participou da discussão teórica, da redação e da elaboração da versão final. JL Pena e GLL Machado-Coelho delinearam o escopo da pesquisa e propuseram o instrumento de coleta do survey. JL Pena também participou da pesquisa empírica. Ambos participaram da revisão do texto e da elaboração de sua versão final. L Heller participou da revisão do texto e da elaboração da versão final. Todos os autores discutiram, leram e aprovaram a versão final do artigo. 


\section{Referências}

1. King $M$, Smith A, Gracey M. Indigenous health part 2: the underlying causes of the health gap. Lancet 2009; 374(9683):76-84.

2. Chor D, Lima CRA. Aspectos epidemiológicos das desigualdades raciais em saúde no Brasil. Cad Saude Publica 2005; 21(5):1586-1594.

3. Gracey M, King M. Indigenous health part 1: determinants and disease patterns. Lancet 2009; 374(9683):6575.

4. Carlos Júnior EAC. Saúde e povos indígenas no Brasil: reflexões a partir do I Inquérito Nacional de Saúde e Nutrição Indígena. Cad Saude Publica 2014; 30(4):855859.

5. Coimbra Júnior CEA, Santos RV, Welch Júnior, Cardoso AM, Souza MC, Garnelo L, Rassi E, Follér M-L, Horta BL. The First National Survey of Indigenous People's Health and Nutrition in Brazil: rationale, methodology, and overview of results. BMC Public Health 2013; 13:52.

6. Cardoso AM, Santos RV, Coimbra Júnior CEA. Mortalidade infantil segundo raça/cor no Brasil: o que dizem os sistemas nacionais de informação? Cad Saude Publica 2005; 21(5):1602-1608.

7. Coimbra Júnior CEA, Santos RV. Perfil Epidemiológico da População Indígena no Brasil: Considerações Gerais. Porto Velho: Centro de Estudos em Saúde do Índio de Rondônia, Universidade Federal de Rondônia. Documento de trabalho $n^{\circ}$ 3. 2001 Mar [acessado 2014 jul 12]; [40 p.]. Disponível em: http://www.cesir.unir.br/ pdfs/doc3.pdf

8. Escobar AL, Coimbra Júnior CEA, Welch Júnior, Horta BL, Santos RV, Cardoso AM. Diarrhea and health inequity among Indigenous children in Brazil: results from the First National Survey of Indigenous People s Health and Nutrition. BMC Public Health 2015; 15:1.

9. Instituto Brasileiro de Geografia e Estatística (IBGE). Censo demográfico 2010: Características Gerais dos Indígenas. Resultados do universo. Rio de Janeiro: IBGE; 2012 [acessado 2015 jun 20]; [245 p.]. Disponível em: http://ftp.ibge.gov.br/Censos/Censo_Demografico_2010/Caracteristicas_Gerais_dos_Indigenas/pdf/ Publicacao_completa.pdf

10. Instituto Socioambiental (ISA). Povos Indígenas no Brasil: Índios emergentes. Brasília: ISA; 2011.

11. Luciano GS. O indio brasileiro: o que você precisa saber sobre os povos indígenas no Brasil de hoje. Brasília: Ministério da Educação; 2006.

12. Verdum R. Etnodesenvolvimento e mecanismos de fomento do desenvolvimento dos povos indígenas: a contribuição do Subprograma Projetos Demonstrativos (PDA). In: Souza Lima AC, Barroso-Hoffmann M, organizadores. Etnodesenvolvimento e Políticas Públicas: Bases para uma Nova Politica Indigenista. Rio de Janeiro; 2002. p. 87-101.

13. Blaser M, Feit HA. Indigenous peoples and development processes: new terrains of struggle. In: Blaser M, Feit HA, Mcrae G, editors. In the way of development: indigenous peoples, life projects, and globalization. London, New York; 2004. p. 1-25.

14. Centro de Documentação Eloy Ferreira da Silva (CEDEFES). Aranã: a luta de um povo no Vale do Jequitinhonha. Contagem: CEDEFES; 2003.
15. Mattos IM. Civilização e Revolta: povos Botocudo e indigenismo missionário na província de Minas [tese]. Campinas: Universidade Estadual de Campinas; 2002.

16. Carvalho LC. Os Aranã e sua indianidade: disputas internas por legitimidade e o reconhecimento oficial como grupo indígena [dissertação]. Belo Horizonte: Universidade Federal de Minas Gerais; 2008.

17. Instituto Brasileiro de Geografia e Estatística (IBGE). Censo 2010: Características da população e dos domicílios: Resultados do Universo. Rio de Janeiro: IBGE; 2011.

18. Pena JL. Perfil sanitário, indicadores demográficos e saúde ambiental após a implantação do distrito sanitário especial indígena: o caso dos Xakriabá em Minas Gerais [dissertação]. Belo Horizonte: Universidade Federal de Minas Gerais; 2004.

19. Heller L. Associação entre cenários de saneamento e diarreia em Betim-MG: o emprego do delineamento epidemiológico caso-controle na definição de prioridades de intervenção [tese]. Belo Horizonte: Universidade Federal de Minas Gerais; 1995.

20. Teixeira JC. Associação entre cenários de saneamento $e$ indicadores de saúde em crianças. Estudo em áreas de assentamento subnormal em Juiz de Fora - MG [tese]. Belo Horizonte: Universidade Federal de Minas Gerais; 2003.

21. Castro EV. No Brasil, todo mundo é índio, exceto quem não é. In: Ricardo B, Ricardo F, organizadores. Povos indígenas no Brasil: 2001/2005. São Paulo: Instituto Socioambiental (ISA); 2006. [acessado $2014 \mathrm{dez} 20$ ]. Disponível em: http://pib.socioambiental.org/files/file/ PIB_institucional/No_Brasil_todo_mundo_\%C3\% A9_\%C3\%ADndio.pdf

22. Marinho GL, Santos RV, Pereira NOM. Classificação dos domicílios "indígenas" no Censo Demográfico 2000: subsídios para a análise de condições de saúde. Rev. bras. estud. popul 2011; 28(2):449-466.

23. Franceschini VLC, Gomes MMF, Gonzaga MR. Vulnerabilidade ao óbito infantil: uma análise do perfil dos nascidos vivos segundo as microrregiões do Vale do Jequitinhonha, 2007. In: Anais do XVII Encontro Nacional de Estudos Populacionais - ABEP; 2010. Caxambu.

24. Instituto Brasileiro de Geografia e Estatística (IBGE). Pesquisa Nacional por Amostra de Domicílios: sintese de indicadores 2012. Rio de Janeiro: IBGE; 2013.

25. Brasil. Ministério do Desenvolvimento Social e Combate à Fome. Nota Técnica: O perfil da Extrema Pobreza no Brasil com base nos dados preliminares do universo do Censo 2010. Brasília; maio de 2011. 7 p. [acessado 2012 jul 01]. Disponível em: http://www.mds.gov.br/ saladeimprensa/noticias/2011/maio.

26. Faustino RC, Novak MSJ, Mileski KG, Ramon PCR, Lança VS, Bernardino MM. O Programa Bolsa Família e o acesso à educação escolar em comunidades indígenas Kaingang e Guarani no Paraná. Pesquisas de Avaliação - MDS 2011; 1:1-18. [acessado 2014 nov 10]. Disponível em: http://aplicacoes.mds.gov.br/sagirmps/ simulacao/sum_executivo/pdf/sumario_119.pdf

27. Costa LF. Perfil Alimentar e Nutricional de Crianças Indígenas da Etnia Pataxó, Cumuruxatiba, Bahia, Brasil [monografia]. Brasília: Universidade Federal de Brasília; 2013. 
28. Favaro T, Ribas DLB, Zorzatto JÚNIOR, Segall-Corrêa AM, Panigassi G. Segurança alimentar em famílias indígenas Teréna, Mato Grosso do Sul, Brasil. Cad Saude Publica 2007; 23(4):785-793.

29. Silva EM. Perfil Epidemiológico e Nutricional de Crianças Indígenas da Etnia Atikum, Pernambuco, Brasil [monografia]. Brasília: Universidade Federal de Brasília; 2014.

30. Quermes PAA, Carvalho JA. Os impactos dos benefícios assistenciais para os povos indígenas. Estudo de Caso em Aldeias Guaranis. Serv. Soc. Soc 2013; 116:769791.

31. Carvalho OMB, Barbosa TV, Bock RB. Ampliação do acesso de famílias indígenas ao cadastro único e ao Programa Bolsa Família. In: Brasil. Ministério do Desenvolvimento Social e Combate à Fome. Secretaria de Avaliação e Gestão da Informação. Povos Indígenas: um registro das ações de desenvolvimento social. Cadernos de Estudos Desenvolvimento Social em Debate. Brasília: 2008. [acessado 2015 mar 15]. Disponível em: http:// aplicacoes.mds.gov.br/sagirmps/ferramentas/docs/caderno\%20-\%2010.pdf

32. Ribeiro EM, Ayres EB, Galizoni FM, Almeida AF, Pereira VG. Programas sociais, mudanças e condições de vida na agricultura familiar do Vale do Jequitinhonha Mineiro. Rev. Econ. Sociol. Rural 2014; 52(2):365-386.

33. Brasil. Ministério de Desenvolvimento Social e Combate à Fome (MDS). Secretaria Nacional de Renda de Cidadania (Senarc). Perfil das Famílias do Cadastro Único para Programas Sociais do Governo Federal. Brasília. 2013. [acessado 2015 jul 01]. Disponível em: http://www.mds.gov.br/biblioteca/secretaria-nacionalde-renda-de-cidadania-senarc/cartilhas/perfil-dasfamilias-do-cadastro-unico/LIVRO_PERFIL_FAMILIAS_BOLSA_com_capa.pdf

34. Moura MM. Os deserdados da terra. Rio de Janeiro: Bertrand Brasil; 1988.

35. Leite ACGA. A modernização do Vale do Jequitinhonha mineiro e o processo de formação do trabalhador "boia fria" em suas condiçães regionais de mobilização do trabalho [dissertação]. São Paulo: Universidade de São Paulo; 2010.

36. Pena JL, Heller L. Saneamento e saúde indígena: uma avaliação na população Xakriabá, Minas Gerais. Eng. Sanit. Ambient 2008; 13(1):63-72.

37. Assis EM, Olivieria, RC, Moreira LE, Pena JL, Rodrigues LC, Machado-Coelho, GL. Prevalência de parasitos intestinais na comunidade indígena Maxakali, Minas Gerais, Brasil, 2009. Cad Saude Publica 2013; 29(4):681-690.
38. Heller L, Moller LM. Saneamento e saúde publica. In: Barros RTV, Chernicharo CAL, Heller L, Von Sperling $\mathrm{M}$, organizadores. Manual de saneamento e proteção ambiental para os municípios. Belo Horizonte: Escola de Engenharia da UFMG; 1995. v. 2. p. 51-61.

39. Coimbra Júnior CEA. Saúde e povos indígenas no Brasil: reflexões a partir do I inquérito Nacional de Saúde e Nutrição Indígena. Cad Saude Publica 2014; 30(4);855859.

40. Instituto Brasileiro de Geografia e Estatística (IBGE). Sistema IBGE de recuperação automática-SIDRA: banco de dados agregados. [acessado 2015 jun 18]. Disponível em: http://www.sidra.ibge.gov.br/cd/cd2010universo.asp?o $=7 \& \mathrm{i}=\mathrm{P}$

41. Santos Júnior HG, Garnelo L. Perfil sociossanitário de crianças indígenas Baniwa do Noroeste Amazônico. Anais Congr Bras Med Fam Comunidade Belém do Pará; 2013. [acessado 2015 mar 28]. Disponível em: http:// www.cmfc.org.br/brasileiro/article/view/702/pdf

42. Giatti LL, Rocha AA, Toledo RF, Barreira LP, Rios L, Pelicione MCF, Mutti LV, Cutolo SA. Condições sanitárias e socioambientais em Iauaretê, área indígena em São Gabriel da Cachoeira, AM. Cien Saude Colet 2007; 12(6):1711-1723.

43. Ferrão J. Relações entre mundo rural e mundo urbano: evolução histórica, situação actual e pistas para o futuro. EURE 2000; 26(78):123-130. [acessado $2015 \mathrm{mar}$ 28]. Disponível em: http://www.redalyc.org/articulo. oa? id $=19607806$

44. Nunes ES. Índios urbanos: dados demográficos e algumas reflexões. In: $26^{a}$ Reunião Brasileira de Antropologia, Associação Brasileira de Antropologia; Porto Seguro; 2008.

45. Coimbra Júnior CEA, Santos RV. Saúde, minorias e desigualdade: algumas teias de inter-relações, com ênfase nos povos indígenas no Brasil. Cien Saude Colet 2000; 5(1):125-132.

Artigo apresentado em 29/08/2014

Aprovado em 29/08/2015

Versão final apresentada em 31/08/2015 